\title{
Addressing Vulnerable Population Needs in the Last Mile to the elimination of mother to child transmission of HIV: (Re)Claiming the HIV Response for Female Sex Workers and Their Children
}

\author{
Avi J. Hakim ${ }^{*}$, Tegan Callahan, Irene Benech, Monita Patel, Michelle Adler, Surbhi Modi, Moses Bateganya, \\ Kae Anne Parris and Trista Bingham
}

\begin{abstract}
As countries strive to eliminate mother-to-child transmission of HIV, female sex workers (FSW) and their children still face barriers to accessing these essential services. Data on FSW uptake of HIV and reproductive health services before, during, and after pregnancy reveal inadequate service utilization. Stigma encountered by FSW in healthcare settings may contribute to low uptake of HIV testing, antiretroviral therapy (ART), and other prevention of motherto-child HIV transmission (PMTCT) services. Coordination between community-based FSW and facility-based PMTCT programs can facilitate successful linkage of pregnant FSW to antenatal services to support PMTCT efforts. We offer a way forward to reach 90-90-90 targets for FSW and their families and eliminate mother-to-child transmission of HIV.
\end{abstract}

Keywords: female sex workers, prevention of mother-to-child transmission, HIV, HIV-exposed infants, orphans and vulnerable children

Nearly four decades into the HIV epidemic, female sex workers (FSW) remain disproportionately burdened compared with other female populations [1]. In low and middle-income countries, the odds of becoming HIV positive is estimated to be 13.5 times greater for FSW than for other reproductive-aged women [2]. HIV prevalence among FSW varies and in Southern Africa, over half of FSW are living with HIV [3-6].

Although data about the HIV epidemic among FSW are becoming increasingly available, there remains a dearth of information about their access to and uptake

\footnotetext{
* Correspondence: hxv8@cdc.gov

US Centers for Disease Control and Prevention, Division of Global HIV and TB, 1600 Clifton Rd, NE, US2-1, Atlanta, GA 30329, USA
}

of sexual and reproductive health (SRH) and prevention of mother-to-child transmission (PMTCT) services. FSW are at risk for unintended pregnancies due to inconsistent condom use, an increased number of sexual partners, and limited access to family planning services [2, 7-9].

The 2016 World Health Organization (WHO) Consolidated Guidelines on the HIV Prevention, Diagnosis and Treatment and Care for Key Populations (KP) includes SRH services amongst the core services to be provided and suggests that PMTCT programs need to consider equity of access, later presentation, and enhanced postpartum and adherence support, but offer no further service delivery recommendations for pregnant, HIVpositive FSW and their infants [10, 11]. Given the

(c) The Author(s). 2020 Open Access This article is licensed under a Creative Commons Attribution 4.0 International License, which permits use, sharing, adaptation, distribution and reproduction in any medium or format, as long as you give appropriate credit to the original author(s) and the source, provide a link to the Creative Commons licence, and indicate if changes were made. The images or other third party material in this article are included in the article's Creative Commons licence, unless indicated otherwise in a credit line to the material. If material is not included in the article's Creative Commons licence and your intended use is not permitted by statutory regulation or exceeds the permitted use, you will need to obtain permission directly from the copyright holder. To view a copy of this licence, visit http://creativecommons.org/licenses/by/4.0/ The Creative Commons Public Domain Dedication waiver (http://creativecommons.org/publicdomain/zero/1.0/) applies to the data made available in this article, unless otherwise stated in a credit line to the data. 
challenges faced by FSW in accessing HIV and SRH services geared toward the general population, we suggest a way forward to support SRH and PMTCT services for FSW.

\section{Sub-optimal SRH and HIV services for FSW}

FSW likely face additional hurdles accessing PMTCT services compared to non-sex workers due to vulnerabilities surrounding sex work, including stigma, limited social support, violence, and poverty $[12,13]$. When diagnosed with HIV, FSW are often referred to health facilities catering to the general population and whose staff may not be sensitized to FSW or their unique needs [14].

Fear of stigma may prevent FSW from disclosing their sex work to service providers not trained to work with them [15]. In Mozambique, although 94.8\% of FSW felt they were treated like everyone else when seeking healthcare, less than half (45.9\%) disclosed to healthcare providers that they sold sex [16].

Qualitative interviews with FSW in four southern African countries revealed that FSW experienced stigma and discrimination when accessing health services leading them to not disclose that they sell sex [15]. Enhanced services for FSW during ANC requires that ANC service providers identify FSW and coordinate efforts with FSW programs to ensure systematic stigma-free and confidential follow-up.

In addition to the stigma due to selling sex or living with HIV, pregnant FSW living with HIV may face multi-layered stigma derived from the combination of these factors (e.g., selling sex while pregnant, being HIV positive and pregnant, being an HIV-positive sex worker). FSW, therefore, may encounter negative attitudes from multiple sources when seeking HIV services-service providers, other sex workers, other women accessing health services, and community members [17-20].

Another vulnerability emerges when pregnant FSW transition from FSW-specific services, that is, services targeting only FSW, to ANC services which target all pregnant women. FSW may become effectively "lost to follow up" if linkage between services is not assured, hampering efforts to monitor their ANC uptake. FSW who are not identified as such at ANC may miss out on differentiated care interventions for HIV prevention and care (e.g., pre-exposure prophylaxis (PrEP), postexposure prophylaxis (PEP), male and female condoms, lubricants, or more frequent HIV testing, and enhanced support for those on ART). Their infants and children may consequently also miss out on opportunities for services, such as those provided by orphans and vulnerable children (OVC) programs.

\section{Antenatal care (ANC) uptake and HIV testing}

Awareness of HIV status among FSW living with HIV ranges from $39.3 \%$ in Papua New Guinea to $64.0 \%$ in Zimbabwe [6, 21]. HIV testing during ANC is the indispensable first step in PMTCT and can provide a testing avenue for women who may not otherwise be tested. FSW mothers in Burkina Faso were more likely than FSW non-mothers to have tested for HIV, for instance [22]. In Ghana, $45 \%$ of FSW who had previously tested for HIV were tested during pregnancy [23]. Though ANC attendance during last pregnancy ranged from $78.5 \%$ among FSW in South Sudan to $94.4 \%$ in South Africa, uptake of HIV testing at ANC is more variable, ranging from $58.9 \%$ in Côte d'Ivoire to $92.0 \%$ in South Sudan $[4,24,25]$.

\section{Linkage to HIV treatment, viral suppression, and HIV-exposed infant care}

According to a 2014 global review, approximately $42 \%$ of all FSW living with HIV were receiving ART [8]. Among all FSW living with HIV in Kampala, Uganda, $37.8 \%$ were on ART and $35.2 \%$ were virally suppressed [26]. In Zimbabwe, $43.3 \%$ of all FSW living with HIV were on ART and $49.5 \%$ were virally suppressed, compared to $66.4 \%$ and $58.2 \%$ among general population women, respectively [6, 27].

Linkage of HIV-infected mothers to ART is critical not only for the mother's own health, but also for PMTCT $[28,29]$. While there are no data on outcomes of HIV-exposed infants (HEI) of FSW, suboptimal awareness of HIV status, linkage to treatment, and viral suppression among FSW suggest their infants may be at a higher risk of MTCT than other infants.

\section{Breastfeeding and continued care after delivery}

If and how quickly FSW mothers return to sex work post-delivery is unclear [3, 22, 25]. Data from Côte d'Ivoire reveal that $58.3 \%$ of sex workers returned to selling sex within 4-6 months post-delivery [25]. Women who test HIV-negative prior to delivery but then resume sex work while breastfeeding are at risk of HIV acquisition and subsequent MTCT.

Like their mothers, children of FSW may interact less with the general health system. Data from South Africa have shown that children of FSW, regardless of the mother's and their own HIV status, experience lower immunization rates and growth than other children [30].

\section{A call to action}

Essential first steps for including FSW in a vision for the elimination of mother to child transmission of HIV (EMTCT)

Ensuring that high quality comprehensive PMTCT services, implemented according to national guidelines, are 
accessible to all FSW is the essential first step for service providers and policy makers interested in achieving the World Health Organization's EMTCT goals [31]. Best practices for increasing service accessibility for KP at the clinic level include: reorganizing clinic setup to increase confidentiality and support disclosure of risk behaviors, non-standard operating hours, and the provision of child care [20].

FSW should be prioritized for PrEP, given their higher risk of HIV acquisition. WHO guidance on Preventing HIV During Pregnancy and Breastfeeding enables prioritization of pregnant, HIV-negative FSW for PrEP [32]. PrEP can facilitate continued FSW engagement with the healthcare system during pregnancy and beyond. Additionally, FSW-focused programs should strengthen the systematic offer of routine HIV testing, provision of male and female condoms, lubricants, postexposure prophylaxis (PEP), STI screening and treatment, and family planning as needed to give women control of their fertility and reduce the risk of HIV acquisition. FSW programs could further provide HIV selftests to pregnant FSW and encourage self-testing at regular intervals during pregnancy and breastfeeding [33]. Infants of FSW living with HIV should be considered high risk and prioritized for enhanced infant postnatal prophylaxis and other key HIV-exposed infant services.

For FSW living with HIV, enhanced HIV services during pregnancy and post-partum periods may include provision of linkage to psychosocial support, ART adherence support for those who need it, testing of all their biological children through an index approach, peer mother programs, orphan and vulnerable children services for their families, active case management or follow up, and multi-month ART dispensing . Such additional support is especially important for FSW as they may be younger and have less social support than other women. As little is known about ART adherence among FSW, they may benefit from being prioritized for point-of-care viral load testing in order to provide rapid interventions for elevated viral loads in order to minimize risk of transmission to partners and infants (if pregnant or breastfeeding), and promote improved clinical outcomes.

\section{Ongoing learning agenda to inform service provision}

Better surveillance data and key population disaggregates for program data are needed to characterize the PMTCT and 90-90-90 cascades for FSW and their infants [34]. More information is needed to characterize the risks, vulnerabilities and other experiences of FSW and their families including concerning mental health, protection, economic insecurity, housing stability, food security, and education and immunization of children.
As FSW and PMTCT programs adopt new strategies to reach FSW, they can engage in continuous quality improvement (CQI) to provide immediate feedback from FSW and service providers to inform and adapt services. Furthermore, evaluation of different models of differentiated service delivery for FSW is warranted and could be used to facilitate integration of KP and ANC/PMTCT services. As a richer evidence base is developed from CQI activities, implementation science, program evaluations, and biobehavioral surveys, other innovations may be identified to support the EMTCT agenda among FSW and their children [48].

The lack of data on FSW uptake of PMTCT services should not hinder efforts to improve FSW uptake of essential services. Best practices for providing services to $\mathrm{KP}$ can be introduced now in FSW, orphans and vulnerable children, and PMTCT programs to close the gap for pregnant and breastfeeding FSW. Full access to HIV and reproductive health services for FSW, including preventing HIV transmission to their children, is possible. Global stakeholders have the tools available today to ensure the EMTCT agenda is accessible to all families.

\section{Abbreviations \\ ANC: Antenatal care; ART: Antiretroviral therapy; BBS: Biobehavioral surveys; EMTCT: Elimination of mother-to-child transmission; FSW: Female sex workers; HEl: Hiv-exposed infants; KP: Key populations; OVC: Orphans and vulnerable children; PMTCT: Prevention of mother-to-child transmission; PEP: Post-exposure prophylaxis; PrEP: Preexposure prophylaxis; SRH: Sexual and reproductive health; STI: Sexually transmitted infection; UNAIDS: JointUnited Nations Programme on HIV/AIDS; WHO: World Health Organization}

\section{Acknowledgements}

Emilia Rivadeneira provided important feedback on an early version of this manuscript.

\section{Disclaimer}

The findings and conclusions in this paper are those of the authors and do not necessarily represent the official position of the funding agencies.

\section{Authors' contributions \\ $A J H, T B, I B$, and MA conceived of the topic for the commentary. AJH, TC, IB, and TB contributed substantially to the writing. MP, MA, SM, MB, and KP reviewed the manuscript. All authors read and approved the final manuscript. \\ Funding \\ This project has been supported by the US President's Emergency Plan for AIDS Relief (PEPFAR) through the US Centers for Disease Control and Prevention (CDC).}

\section{Availability of data and materials}

Data sharing is not applicable to this article as no datasets were generated or analysed during the current study.

Ethics approval and consent to participate

No ethical approval or consents were required for the development of this review.

Consent for publication

Not applicable. 


\section{Competing interests}

We have no competing interests to report.

Received: 7 January 2020 Accepted: 15 June 2020

Published online: 26 June 2020

\section{References}

1. Willis B, Welch $\mathrm{K}$, Onda S. Health of female sex workers and their children: a call for action. Lancet Glob Health. 2016;4(7):e438-e9.

2. Baral S, Beyrer C, Muessig K, Poteat T, Wirtz AL, Decker MR, et al. Burden of HIV among female sex workers in low-income and middle-income countries: a systematic review and meta-analysis. Lancet Infect Dis. 2012; 12(7):538-49.

3. Lancaster KE, Powers KA, Lungu T, Mmodzi P, Hosseinipour MC, Chadwick K, et al. The HIV Care Continuum among Female Sex Workers: A Key Population in Lilongwe. Malawi PLoS One. 2016;11(1):e0147662.

4. UCSF AHIW. South Africa Health Monitoring Survey (SAMHS). An Integrated Biological and Behavioural Survey among Female Sex Workers, South Africa 2013 - 2014 Final Report. San Francisco: UCSF; 2014.

5. Fonner VA, Kerrigan D, Mnisi Z, Ketende S, Kennedy CE, Baral S. Social cohesion, social participation, and HIV related risk among female sex workers in Swaziland. PLoS One. 2014;9(1):e87527.

6. Cowan FM, Davey CB, Fearon E, Mushati P, Dirawo J, Cambiano V, et al. The HIV Care Cascade Among Female Sex Workers in Zimbabwe: Results of a Population-Based Survey From the Sisters Antiretroviral Therapy Programme for Prevention of HIV, an Integrated Response (SAPPH-IRe) Trial. J Acquir Immune Defic Syndr. 2017;74(4):375-82.

7. Lafort $Y$, Jocitala $O$, Candrinho B, Greener L, Beksinska M, Smit JA, et al. Are HIV and reproductive health services adapted to the needs of female sex workers? Results of a policy and situational analysis in Tete, Mozambique. BMC Health Serv Res. 2016;16:301.

8. Mountain E, Mishra S, Vickerman P, Pickles M, Gilks C, Boily MC. Antiretroviral therapy uptake, attrition, adherence and outcomes among HIV-infected female sex workers: a systematic review and meta-analysis. PLoS One. 2014; 9(9):e105645.

9. Soto RJ, Ghee AE, Nunez CA, Mayorga R, Tapia KA, Astete SG, et al. Sentinel surveillance of sexually transmitted infections/HIV and risk behaviors in vulnerable populations in 5 Central American countries. J Acquir Immune Defic Syndr. 2007:46(1):101-11.

10. WHO. Consolidated Guidelines on the HIV Prevention, Diagnosis and Treatment and Care for Key Populations, 2016 Update; 2016.

11. Beard J, Biemba G, Brooks MI, Costello J, Ommerborn M, Bresnahan M, et al. Children of female sex workers and drug users: a review of vulnerability, resilience and family-centred models of care. J Int AIDS Soc. 2010;13(Supp 2):S6.

12. Lancaster KE, Cernigliaro D, Zulliger R, Fleming PF. HIV care and treatment experiences among female sex workers living with HIV in sub-Saharan Africa: A systematic review. Afr J AIDS Res. 2016;15(4):377-86.

13. Scorgie F, Chersich MF, Ntaganira I, Gerbase A, Lule F, Lo YR. Sociodemographic characteristics and behavioral risk factors of female sex workers in sub-saharan Africa: a systematic review. AIDS Behav. 2012;16(4): 920-33.

14. Dhana A, Luchters S, Moore L, Lafort Y, Roy A, Scorgie F, et al. Systematic review of facility-based sexual and reproductive health services for female sex workers in Africa. Glob Health. 2014;10:46.

15. Scorgie F, Nakato D, Harper E, Richter M, Maseko S, Nare P, et al. 'We are despised in the hospitals': sex workers' experiences of accessing health care in four African countries. Cult Health Sex. 2013;15(4):450-65.

16. Lafort $Y$, Lessitala F, Candrinho B, Greener L, Greener R, Beksinska M, et al. Barriers to HIV and sexual and reproductive health care for female sex workers in Tete, Mozambique: results from a cross-sectional survey and focus group discussions. BMC Public Health. 2016;16:608.

17. Hargreaves JR, Busza J, Mushati P, Fearon E, Cowan FM. Overlapping HIV and sex-work stigma among female sex workers recruited to 14 respondent-driven sampling surveys across Zimbabwe, 2013. AIDS Care. 2017:29(6):675-85.

18. King EJ, Maman S, Bowling JM, Moracco KE, Dudina V. The influence of stigma and discrimination on female sex workers' access to HIV services in St. Petersburg, Russia. AIDS Behav. 2013;17(8):2597-603.

19. Buregyeya E, Naigino R, Mukose A, Makumbi F, Esiru G, Arinaitwe J, et al. Facilitators and barriers to uptake and adherence to lifelong antiretroviral therapy among HIV infected pregnant women in Uganda: a qualitative study. BMC Pregnancy Childbirth. 2017;17(1):94.

20. McMahon SA, Kennedy CE, Winch PJ, Kombe M, Killewo J, Kilewo C. Stigma, Facility Constraints, and Personal Disbelief: Why Women Disengage from HIV Care During and After Pregnancy in Morogoro Region, Tanzania. AIDS Behav. 2017:21(1):317-29.

21. Kelly-Hanku AB, Willie S, Narakobi B, Amos-Kuma R, Gabuzzi A, Pekon J, Kupul S, Aeno M, Neo HB, Ase R, Nembari S, Hou J, Dala P, Weikum N, Kaldor D, Vallely J, A Hakim AJ. 90-90-90 and the HIV continuum of Care How well is Papua New Guinea doing amongst Key Populations? Paris: IAS; 2017

22. Papworth E, Schwartz S, Ky-Zerbo O, Leistman B, Ouedraogo G, Samadoulougou $C$, et al. Mothers who sell sex: a potential paradigm for integrated HIV, sexual, and reproductive health interventions among women at high risk of HIV in Burkina Faso. J Acquir Immune Defic Syndr. 2015;68(Suppl 2):S154-61.

23. Adu-Oppong A, Grimes RM, Ross MW, Risser J, Kessie G. Social and behavioral determinants of consistent condom use among female commercial sex workers in Ghana. AIDS education and prevention : official publication of the International Society for AIDS Education. 2007;19(2):16072

24. Health SSMo. A Bio-Behavioral HIV Survey of Female Sex Workers in Juba. The Eagle Survey: South Sudan; 2016.

25. Schwartz S, Papworth E, Thiam-Niangoin M, Abo K, Drame F, Diouf D, et al. An urgent need for integration of family planning services into HIV care: the high burden of unplanned pregnancy, termination of pregnancy, and limited contraception use among female sex workers in Cote d'Ivoire. J Acquir Immune Defic Syndr. 2015;68(Suppl 2):S91-8.

26. Doshi RH, Sande E, Ogwal M, Kiyingi H, Mclntyre A, Kusiima J, et al. Progress toward UNAIDS 90-90-90 targets: A respondent-driven survey among female sex workers in Kampala, Uganda. PLoS One. 2018;13(9):e0201352.

27. Ministry of Health and Child Care (MOHCC) Z. Zimbabwe Population-Based HIV Impact Assessment (ZIMPHIA) 2015-16: First Report. Harare: MOHCC; 2017.

28. Mandelbrot L, Tubiana R, Le Chenadec J, Dollfus C, Faye A, Pannier E, et al. No perinatal HIV-1 transmission from women with effective antiretrovira therapy starting before conception. Clin Infect Dis. 2015;61(11):1715-25.

29. Myer L, Phillips TK, McIntyre JA, Hsiao NY, Petro G, Zerbe A, et al. HIV viraemia and mother-to-child transmission risk after antiretroviral therapy initiation in pregnancy in Cape Town. South Africa HIV Med. 2017;18(2):808.

30. Schwartz SK, SMcingana MR, Lambert A, Srivatsan A, Phaswana-Mafuya V, Hausler N, Baral S H. Assessing HIV prevalence and health outcomes of children of female sex workers in Port Elizabeth, South Africa to guide PMTCT programming for vulnerable populations. Paris: IAS; 2017.

31. WHO. Global guidance on criteria and processes for validation: elimination of mother-to-child transmission (EMTCT) of HIV and syphilis. Geneva: WHO; 2016.

32. WHO. Preventing HIV during pregnancy and breastfeeding in the context of PrEP. Geneva; 2017.

33. WHO. Guidelines on HIV self-testing and partner notification, Supplement to consolidated guidelines on HIV testing services. Geneva; 2016.

34. Hakim AJ, MacDonald V, Hladik W, Zhao J, Burnett J, Sabin K, et al. Gaps and opportunities: measuring the key population cascade through surveys and services to guide the HIV response. J Int AIDS Soc. 2018;21(Suppl 5):e25119.

\section{Publisher's Note}

Springer Nature remains neutral with regard to jurisdictional claims in published maps and institutional affiliations. 